\title{
Perjuangan Diplomasi Indonesia
}

\section{Melani}

90100121091

\section{Prodi Ekonomi Islam Kelas C UIN Alauddin Makassar \\ E-mail: melani.010503@gmail.com}

\section{PENDAHULUAN}

Pada masa sekarang ini penelitian sejarah sangat penting untuk dilakukan. Sejarah harus diperkenalkan kepada masyarakat luas sebab jika sejarah itu tidak diperkenalkan maka nantinya generasi berikutnya tidak akan mengetahui sejarah yang Pernah terjadi. Sejarah harus tetap dipelajari dalam kehidupan sehari-hari dan penting juga menghargai jasa-jasa pahlawan yang telah gugur. Penelitian sejarah adalah penelitian yang memperkenalkan atau mengulas kembali peristiwa-peristiwa yang mempunyai sejarah atau peristiwa tersebut pernah terjadi setelah ataupun sebelum kemerdekaan Indonesia. Generasi milenial atau generasi muda harus memiliki pengetahuan sejarah yang banyak. Sebab penelitian sejarah sangat banyak memberi wawasan baru terkait peristiwa masa lampau yang bisa dijadikan penunjang dalam kehidupan bermasyarakat.

Melihat generasi millenial atau generasi muda di era industry 4.0 atau di era teknologi informasi ini, Pelu adanya pendidikan sejarah. Seperti yang akan dibahas dalam Penelitian sejarah ini, yaitu mengenai Perjanjian Linggarjati, Agresi Militer (I,II), Tujuan Roem Royen , Konferensi Meja Bundar (KMB), Perjanjian Renville dan bagaimana pembubaran RIS serta proses terbentuknya NKRI. Penelitian ini sebagai pengenalan dan menambah kajian terkait sejarah perjuangan diplomasi Indonesia. Sejarah sangat penting dalam bentuk apapun, baik dalam bentuk sikap bijaksana dan berkarakter.

Penelitian ini menarik untuk diteliti, sebab semua peristiwa tersebut dapat menambah wawasan kita mengenai perjuangan diplomasi Indonesia. Peristiwa tersebut terjadi di masa masa diplomasi Indonesia, bagaimana rakyat Indonesia berjuang hingga terbentuklah Negara Kesatuan Republik Indonesia (NKRI). Maka berdasarkan pendahuluan diatas, peneliti tertarik menulis penelitian ini dengan mengangkat tema "Perjuangan Diplomasi Indonesia". 


\section{HASIL DAN PEMBAHASAN}

\section{A. Perjanjian Linggarjati 11-15/11/1946}

Perjanjian Linggarjati merupakan Perjanjian yang muncul setelah Belanda melakukan serangan pasca diumumkan kemerdekaan Indonesia 17 Agustus 1945. Perjanjian Linggarjati merupakan jalan bagi Indonesia untuk mendapatkan pengakuan dari dunia internasional (Sari, dkk,2014: 12).

Adapun tokoh-tokoh dalam Perjanjian Linggarjati adalah sebagai berikut:

a. Delegasi Belanda: Hubertus van Mook dan Prof. Dr. Ir. W. Schermerhorn

b. Delegasi Indonesia: Soetan Sjahrir, A.K. Gani, Amir Sjarifuddin, Soesanto Tirtoprodjo, Mohammad Roem, dan Ali Boediardjo

c. Delegasi Inggris (Penengah): Lord Inverchapel dan Lord Killearen

Adapun hasil dari perjanjian Linggarjati adalah sebagai berikut:

1. Belanda mengakui kekuasaan defacto Indonesia (JawaMadura,dan Sumatera) daerah yang dikuasai Belanda dan sekutu akan di kembalikannya

2. Berangsur-angsur di bentuk Negara Indonesia

3. Di bentuk Negara Indonesia Serikat (NIS)

4. Pemerintah Belanda dan RI akan bentuk Uni Indonesia-Belanda NIS dan Uni

5. Indonesia - Belanda selesai sebelum 1/1/1949

6. Pemerintah RI mengakui akan memulihkan dan lindungi hak milik asing

7. Pemerintah Rid an Belanda sepakat untuk kurangi jumlah tentara kalau ada perselisiha, akan di selesaikan oleh komite arbitrase.

Dengan tercapainya persetujuan Linggarjati tanggal 15 November 1946 yang kemudian disyahkan tanggal 25 Maret 1947 di Jakarta, justru membuat suhu politik di Indonesia semakin keruh. (Hardyanto, F. Y. 2010).

\section{B. Agrasi Militer I}

a. Pada tanggal 21/7/1947 Belanda menyerang Indonesia. Menguasai seluruh pelabuhan di Jawa. Penangkapan orang China di Jawa Barat bangsawan di Sumatera di bunuh.

b. Pada tanggal 29/8/1947 Belanda deklarasikan garis demarkasi Van Mook yang membuat wilayah Indonesia lebih sedikit. 
c. Pada tanggal 18/9/1947 Komisi 3 negara di bentuk untuk menyelesaikan masalah.

\section{Perjanjian Renville}

Perjanjian renville adalah perjanjian antara Indonesia dengan Belanda yang dilakukan di atas kapal perang milik Amerika Serikat bernama USS Renville pada 17 Januari 1948. Perundingan dilaksanakan di atas kapal perang milik Amerika Serikat, USS Renville. Renville adalah di Kapal Perang AS, USS Renville. Karena itu disebut perjanjian Renville (Jurnal ponsel, 2011)

Adapun hasil dari Perjanjian Renville adalah sebagai berikut:

1. Upaya untuk menyelesaikan masalah di Agresi Militer 1

2. Deklarasi Indonesian di pimpin Amir Syarifuddin

3. Abdul Kadir Wijoyoatmojo perjanjian di adakan di atas kapal Renville

4. Garis demarkasi Van Mook di terima

5. Sepakat untuk menyelesaikan masalah secara damai

6. Kedaulatan Indonesia berada di tangan Belanda selama masa peralihan

\section{Agresi Militer II}

1. Sudah ada tanda-tanda Belanda akan langgar Renville

2. Pada tanggal 19/12/1947 Agresi Militer II

3. Ibu kota Jogjakarta berhasil di kuasai

4. Pimpinan Negara di tawan Belanda

5. Syarifuddin Prawiranegara membentuk PDRI dengan ibu kota Bukit Tinggi.

6. Panglima Sudirman melakukan perang Gerilya

7. Pada tanggal 24/12/1947 DK PBB membuat resolusi agar Indonesia dan Belanda berhenti perang dan memerintahkan Belanda untuk memebebaskan tahanan politik.

Sebagaimana diketahui bahwa Pemerintah Belanda sebenarnya tidak rela begitu saja untuk melepaskan wilayah jajahannya di nusantara melalui peristiwa Proklamasi Kemerdekaan Bangsa Indonesia tanggal 17 Agustus 1945, dengan demikian maka Belanda mencoba menempuh berbagai cara agar dapat kembali menguasai tanah air, baik melalui meja perundingan maupun dengan aksi militernya yang pertama pada 20 Juli 1947 yang akhirnya dihentikan atas dasar Persetujuan Renville (Sugiarto Lesmana, jurnal artefak, 2013). 


\section{E. Persetujuan Roem Royen 14/4/1949}

Adapun tokoh-tokoh dalam Persetujuan Roem Royen adalah sebagai berikut:

1. Delegasi Indonesia : Mohammad Roem

2. Delegasi Belanda : Herman van Roijen (Royen)

3. Delegasi AS : Merle Cochran

Adapun hasil dari persetujuan ini adalah sebagai berikut:

1. Indonesia akan hentikan perang Gerilya, ikut dalam KMB di Den Haag

2. Belanda mengembalikan RI ke Jogja, bebaskan seluruh politik dan menghentikan gerakan militer, dan menyetujui RI sebagai bagian dari NIS

Setelah ditandatanganinya Persetujuan Roem-Roijen, maka tentunya muncul beragam reaksi. Reaksi yang cukup keras datang dari Wakil Tinggi Mahkota Belanda untuk wilayah Indonesia, Dr. L.J.M. Beel, sekalipun dia turut menyetujui persetujuan tersebut, namun sebenarnya Beel menentang Pemerintah Belanda untuk tunduk pada ruling Dewan Keamanan LBB tanggal 23 Maret 1949 sehingga terjadilah perundingan dengan pihak Republik Indonesia (Sugiarto Lesmana, jurnal artefak, 2013).

\section{F. Konferensi Meja Bundar (KMB) Den Haag, 23/8/1949}

Konferensi Meja Bundar (KMB) yang diselenggarakan di Den Haag pada tanggal 23 Agustus sampai dengan tanggal 2 November 1949 telah mencapai suatu persetujuan. Berdasarkan persetujuan itu pada tanggal 27 Desember 1949 Kerajaan Belanda menyerahkan kekuasaan atas seluruh wilayah Hindia Belanda, kecuali Irian Barat kepada Republik Indonesia Serikat (RIS) (Astuti, L. N. 2011). Adapun hasil dari Konferensi Meja Bundar adalah sebagai berikut:

1. Belanda mengakui RIS sebagai Negara merdeka dan berdaulat

2. Masalah Irian Barat akan di selesaikan setahun kemudian corak

3. Pemerintahan RIS akan di atur dengan konstitusi oleh para delegasi di KMB

4. Akan di bentuk Uni Indonesia-Belanda yang sifatnya longgar

5. RIS harus bayar hutang Hindia Belanda

6. RIS akan kembalikan hak milik Belanda dan kasih izin untuk perusahaan Belanda.

Pada tanggal 16/12/1949 Soekarno terpilih jadi Presiden RI sementara di isi oleh Mr. Assaat (Ketua KNIP). Dan kemudian RIS berakhir, dan terbentuklah NKRI. 


\section{DAFTAR PUSTAKA}

Hoesein, R. (2010). Terobosan Sukarno dalam Perundingan Linggarjati. Penerbit Buku Kompas.

Hardyanto, F. Y. (2010). Perang mempertahankan kemerdekaan di Kebumen tahun 1945-1950.

Astuti, L. N. (2011). Perjuangan Politik Mohammad Hatta pada Masa Sistem Pemerintahan Parlementer (1948-1956).

Sugiarto Lesmana (2013) Jurnal Artefak. Perundingan Roem-Roijen Dalam Perjuangan Mempertahankan Kemerdekaan Republik Indonesia Tahun 1949

Budiman, A. (2019). Sejarah diplomasi roem-roijen dalam perjuangan mempertahankan kemerdekaan republik indonesia tahun 1949. Jurnal Wahana Pendidikan, 4(1), 86-112.

Susilo, A., \& Wulansari, R. (2021). Perjanjian Linggarjati (Diplomasi dan Perjuangan Bangsa Indonesia Tahun 1946-1947). Criksetra: Jurnal Pendidikan Sejarah, 10(1), 30-42. 